\title{
Localization of Integrin Receptors for Fibronectin, Collagen, and Laminin in Human Skin \\ Variable Expression in Basal and Squamous Cell Carcinomas
}

\begin{abstract}
Juha Peltonen, Hannu Larjava, ${ }^{\star}$ Sirkku Jaakkola, Harvey Gralnick, ${ }^{\ddagger}$ Steven K. Akiyama, ${ }^{\star \$}$ Susan S. Yamada, ${ }^{*}$ Kenneth M. Yamada, ${ }^{*}$ and Jouni Uitto

Departments of Dermatology, Biochemistry, and Molecular Biology, Jefferson Medical College, and Section of Molecular Dermatology, Jefferson Institute of Molecular Medicine, Thomas Jefferson University, Philadelphia, Pennsylvania 19107; ${ }^{\ddagger}$ Clinical Pathology Department, Clinical Center, and *Membrane Biochemistry Section, Laboratory of Molecular Biology, National Cancer Institute, National Institutes of Health, Bethesda, Maryland 20892; and ${ }^{\S}$ Departments of Biochemistry and Oncology, Howard University Cancer Center, Washington, District of Columbia 20060
\end{abstract}

\begin{abstract}
VLA integrins in human skin were examined by indirect immunofluorescence utilizing antibodies recognizing the $\beta_{1}, \alpha_{2}, \alpha_{3}$, or $\alpha_{5}$ subunits. Staining of fetal, newborn, or adult skin with antibodies to $\beta_{1}, \alpha_{2}$, or $\alpha_{3}$ subunits gave essentially similar staining patterns: intense staining was associated with the basal layer of the epidermis, hair follicles, and blood vessel walls. The $\alpha_{5}$ subunit could be detected only in epidermis and the inner root sheath of hair follicles in fetal skin. In epidermis, the staining reaction for the $\beta_{1}$ subunit was not only found in sites interfacing with the basement membrane zone, but also around the entire periphery of these cells. We speculate that these receptors might have previously unrecognized functions in cell-cell interactions or that these findings may suggest the presence of previously unrecognized ligands in the intercellular spaces of keratinocytes. Examination of nine nodular basal cell carcinomas revealed a prominent staining reaction with anti- $\boldsymbol{\beta}_{1}$ and anti- $\alpha_{3}$ antibodies at the periphery of the tumor islands. In contrast, staining of five squamous cell carcinomas revealed either the absence of integrins or altered and variable expression. Thus, matrix components and their receptors may participate in modulation of growth, development, and organization of human skin.
\end{abstract}

\section{Introduction}

Extracellular matrix plays an important role in the attachment, growth, and spreading of epithelial cells, such as keratinocytes, as well as in the regulation of differentiation and gene expression. Extracellular matrix components expressing such activities include fibronectin, laminin, and collagens (1-4). Interactions of extracellular matrix with cells are mediated, at least in part, by a group of cell surface receptor molecules belonging to the integrin superfamily (5-8). Each integrin receptor consists of two different subunits, designated $\alpha$ and $\beta$ (5-8). All integrins of the fibronectin receptor/very

Address reprint requests to Dr. Uitto, Department of Dermatology, Rm. M-46 Jefferson Alumni Hall, Thomas Jefferson University, 1020 Locust Street, Philadelphia, PA 19107. 1989.

Received for publication 20 April 1989 and in revised form 29 June

J. Clin. Invest.

(c) The American Society for Clinical Investigation, Inc.

$0021-9738 / 89 / 12 / 1916 / 08 \quad \$ 2.00$

Volume 84, December 1989, 1916-1923 late antigen (VLA) ${ }^{1}$ family share a common $\beta_{1}$ subunit, whereas the specificity for ligand binding is provided by the $\alpha$ subunit. Among these integrins, the $\alpha_{2}$ subunit facilitates specific binding of the receptor to collagenous ligands that include type I and IV collagens. The $\alpha_{3}$ subunit has a broad specificity, mediating the binding of several ligands that include fibronectin, laminin, and type I and IV collagens. The integrin receptor containing the $\alpha_{5}$ subunit is specific for high-affinity binding of fibronectin (7-11).

The components of the basement membrane at the dermal-epidermal junction serve several functions. For example, type IV collagen, which interacts with other basement membrane components, has been suggested to serve as a preferential attachment substrate (12) and as an effective spreading agent (13) for cultured keratinocytes. Laminin, a noncollagenous glycoprotein consisting of three distinct subunits, has several domains with biological activities, including heparin binding, neurite outgrowth-stimulating activity, and high-affinity cell adhesion (4). The latter activity may be mediated, in part, by the specific amino acid sequences RGD and YIGSR, which have been identified in human laminin A and B1 chains, respectively (14).

The extracellular matrix of connective tissue probably participates in the cell growth and invasiveness associated with malignant cutaneous tumors (15). For example, fibronectin, a ubiquitous noncollagenous glycoprotein, plays a role in epidermal healing by enhancing the migration of keratinocytes $(13,16)$. Fibronectin has also been shown to be particularly abundant in the stroma of basal cell carcinomas (BCC) (17-20), and it has been recently proposed that the presence of fibronectin may explain the relatively benign clinical phenotype of these lesions (20). Since the effects of fibronectin, laminin, and collagenous extracellular matrix components, all present both in normal skin and in cutaneous tumors $(17,20$, 21 ), are potentially mediated by receptors of the integrin family, we have utilized immunocytochemical techniques to examine the expression of receptors containing $\beta_{1}, \alpha_{2}, \alpha_{3}$, and $\alpha_{5}$ subunits in fetal, neonatal, and adult skin from normal human subjects, as well as in basal and squamous cell carcinomas.

\section{Methods}

Tissue specimens. Normal human skin was obtained from a 19-wk-old fetus, from the foreskin of newborn infants, or from adult individuals

1. Abbreviations used in this paper: $\mathrm{BCC}$, basal cell carcinoma; PAP, peroxidase antiperoxidase; TBS, Tris-buffered saline; VLA, very late antigen. 
in connection with cosmetic surgical procedures or removal of various benign cutaneous lesions. BCC specimens were obtained from nine patients in the context of removal of the lesions by Mohs micrographic surgery. Squamous cell carcinoma specimens were similarly obtained from five lesions in four patients. All tissue specimens were snap-frozen and sectioned with a cryomicrotome (20).

Indirect immunofluorescence. For indirect immunofluorescence, $5-\mu \mathrm{m}$ frozen sections were rinsed with Tris-buffered saline (TBS, pH 7.6), and preincubated for $15 \mathrm{~min}$ with TBS containing $1 \%$ bovine serum albumin (BSA). The samples were then exposed to primary antibody in appropriate dilutions (in TBS-BSA) overnight at $4^{\circ} \mathrm{C}$. The sections were washed in TBS for $60 \mathrm{~min}$ with five changes, and incubated either with fluorescein isothiocyanate (FITC)- or with tetramethyl-rhodamine isothiocyanate-conjugated secondary antibodies (Miles Laboratories, Inc., Elkhart, IN). After a 60-min incubation at room temperature, the sections were washed with TBS for $60 \mathrm{~min}$, rinsed with distilled water, and examined with a fluorescence microscope (Optiphot, Nikon Inc., Garden City, NY), equipped with filters for detection of FITC and tetramethyl-rhodamine isothiocyanate. Representative sections were photographed using Tri-X film (Eastman Kodak Co., Rochester, NY). In control reactions, the primary antibody was omitted or replaced with sera from nonimmunized animals. Faint uniform background only was observed in all controls (20).

Peroxidase antiperoxidase (PAP) immunostaining. PAP detection was a slight modification of the method previously described in detail (22). Briefly, $5-\mu \mathrm{m}$ sections were incubated in $0.01 \mathrm{M} \mathrm{HCl}$ containing $10 \mathrm{U} / \mathrm{ml}$ pepsin (Sigma Chemical Co., St. Louis, MO). Endogenous peroxidase activity was blocked by incubating the sections in $0.3 \%$ hydrogen peroxide in methyl alcohol. To prevent nonspecific antibody binding, the sections were preincubated for $30 \mathrm{~min}$ in a solution containing $1 \%$ BSA in TBS. For antibody staining, sections were first incubated with a primary antibody at appropriate dilutions. Swine anti-rabbit antiserum (Accurate Chemical \& Scientific Corp., Westbury, NY) was then used as the linking antibody and the sections were incubated with rabbit PAP (Accurate Chemical \& Scientific Corp.). Peroxidase activity was detected by incubation with 3,3'-diaminobenzidine tetrahydrochloride in $0.01 \% \mathrm{H}_{2} \mathrm{O}_{2}$.

Antibodies. The primary antibodies utilized in this study are indicated in Table I. Characterization of antibodies 3847 and J143 has been reported earlier (23-25). Properties of the other antibodies are to be published elsewhere, and are briefly as follows. Antibody F17-6D7 is a mouse monoclonal antibody raised against human platelets that binds specifically to glycoprotein Ia/IIa (26). Antibodies 13 and 16 are both $\mathrm{IgG}_{2 \mathrm{a}}$ of rat origin raised against purified human fibronectin receptor. Antibody 13 recognizes both the mature and precursor forms

Table I. Characteristics of Antibodies to Human Integrin Subunits

\begin{tabular}{|c|c|c|c|}
\hline $\begin{array}{l}\text { Antibody } \\
\text { code }\end{array}$ & Antigen recognized & Immunogen* & Type $^{\ddagger}$ \\
\hline 3847 & $\alpha_{5} / \beta_{1}$ & $\begin{array}{l}\text { Placental FN } \\
\text { receptor }\end{array}$ & Rabbit, polyclonal \\
\hline 13 & $\begin{array}{c}\beta_{1} \text { (extracellular } \\
\text { domain) }\end{array}$ & $\begin{array}{l}\text { Placental FN } \\
\text { receptor }\end{array}$ & Rat, monoclonal \\
\hline F17-6D7 & $\begin{array}{l}\alpha_{2} \text { (extracellular } \\
\text { domain) }\end{array}$ & Platelets & $\begin{array}{l}\text { Mouse, } \\
\text { monoclonal }\end{array}$ \\
\hline $\mathrm{J} 143$ & $\alpha_{3}$ & $\begin{array}{l}\text { Bladder cancer } \\
\text { cells }\end{array}$ & $\begin{array}{l}\text { Mouse, } \\
\text { monoclonal }\end{array}$ \\
\hline 16 & $\begin{array}{c}\alpha_{5} \text { (extracellular } \\
\text { domain) }\end{array}$ & $\begin{array}{l}\text { Placental FN } \\
\text { receptor }\end{array}$ & Rat, monoclonal \\
\hline
\end{tabular}

Abbreviation: FN, fibronectin.

* For details of antigen preparation and immunization, see text.

${ }^{\ddagger}$ All antibodies are of IgG type. of $\beta_{1}$ subunits according to immunoprecipitation and biological specificity criteria. Antibody 16 recognizes $\alpha_{5}$ subunits according to immunoprecipitation criteria. Both antibodies 13 and 16 are described in detail elsewhere (27).

Staining of cultured human skin fibroblasts was used as a positive control for all antibodies utilized in this study. Distinct staining reaction of the cultured cells was noted indicating immunoreactivity of the antibodies.

The monoclonal antibodies were used at a final IgG concentration of $50 \mu \mathrm{g} / \mathrm{ml}$. The polyclonal anti-human fibronectin receptor antiserum 3847 was used at a 1:100 dilution. Monoclonal antibodies to human type IV collagen were purchased from ICN Biochemicals (Lisle, IL).

\section{Results and Discussion}

Normal skin. To characterize the overall distribution of integrins in normal human skin, sections were first stained with monoclonal antibody 13 recognizing the extracellular domain of subunit $\beta_{1}$, the subunit common to all members of the VLA family of the integrin receptor superfamily. The results revealed intense staining associated with the plasma membranes of basal keratinocytes in fetal, newborn, and adult skin (Fig. 1). In fetal skin, the staining was most prominent along the plasma membranes at lateral and upper surfaces of basal cells (Fig. $1 d$ ). In contrast, in adult skin the staining reaction was more prominent along the basal surface of the basal cells apposing the dermal-epidermal basement membrane, although present in lower amounts also along all apical-lateral surfaces of basal cells (Fig. $1 f$ ). Assuming that the epitopes were not masked, these observations suggest that subunit $\beta_{1}$ integrin receptors are less relevant to epidermal cell adhesion to the basement membrane in fetal skin, but may play an important role in the intercellular adhesion. A few distinct areas of dermis also stained positively with this antibody and some of this staining appeared to be in association with small blood vessels, glandular epithelia, or hair follicles (Fig. 1, $a-c$ ). Essentially identical staining patterns were obtained with anti- $\beta_{1}$ monoclonal antibody 13 and polyclonal antibody 3847 raised against the placental fibronectin receptor complex $\left(\alpha_{5} / \beta_{1}\right)$. The similarity of staining is consistent with Western blot analyses indicating that 3847 is directed primarily against $\beta_{1}$ subunit epitopes (25). These observations suggest that integrins are relatively abundant in human epidermis, primarily in the basal layer. They are also in good agreement with those of De Strooper et al. (28), described for adult human skin.

In further studies, specific monoclonal antibodies recognizing the $\alpha_{2}, \alpha_{3}$, or $\alpha_{5}$ integrin subunits were used for immunostaining, so as to allow comparative identification of specific integrins in human skin. First, skin specimens were stained with monoclonal antibody recognizing the $\alpha_{2}$ subunit (F17-6D7). The results indicated positive staining in fetal, neonatal, and adult epidermis, primarily associated with the basal cell layer (Fig. 2, $a-c$ ). No reaction was detected in the dermis. Staining of fetal skin with the $\mathrm{J} 143$ antibody recognizing the $\alpha_{3}$ subunit revealed an immunoreaction closely resembling that obtained with the monoclonal antibody recognizing the $\alpha_{2}$ subunit (Fig. 2, $d-f$ ). In addition, however, clearly detectable expression was noted in association with dermal capillaries (Fig. 2, $e$ and $f$ ). Somewhat diffuse staining reaction was occasionally noted in the most superficial layer of the epidermis (see Figs. $1, b$ and $e$, and $2 b, c, e$, and $f$ ), when stained with antibodies to $\beta_{1}, \alpha_{2}$, and $\alpha_{3}$, but this reaction was considered 

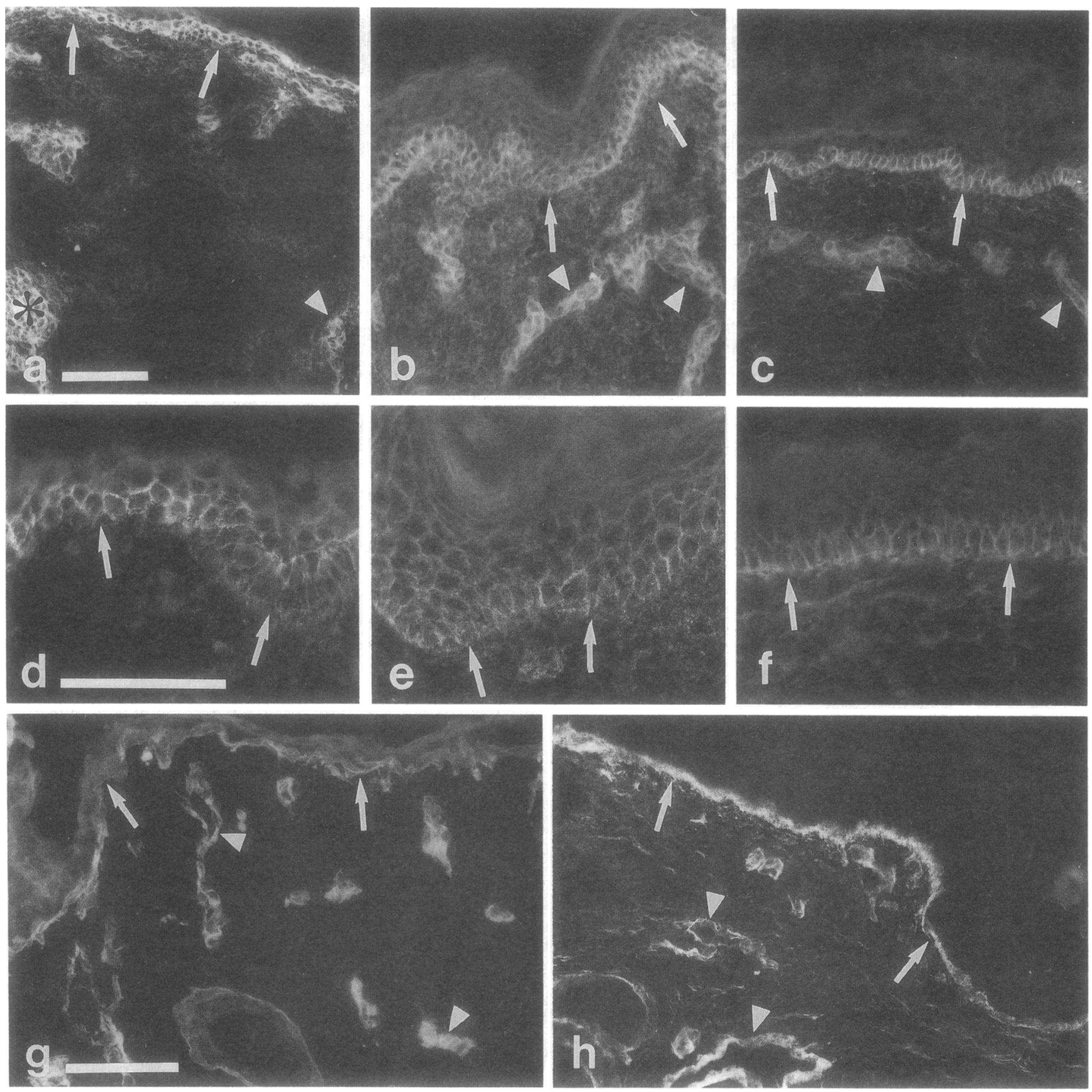

Figure 1. Expression of integrin receptors and type IV collagen epitopes in fetal $(a, d, g)$, neonatal $(b, e)$, and adult $(c, f, h)$ human skin. Staining with polyclonal antibody to the $\beta_{1} / \alpha_{5}$ receptor complex $(a-c)$ or with monoclonal antibody to $\beta_{1}$ subunit $(d-f)$ of human integrin receptor complexes. Note the staining of the basal layer of epidermal keratinocytes (arrows), hair follicle (asterisk), and dermal blood vessel walls (arrowheads). Antibody to type IV collagen $(g, h)$ reveals the basement membrane zone at the dermal-epidermal junction (arrows), and the vascular basement membranes (arrowheads). Bars, $100 \mu \mathrm{m}$.

nonspecific, since this layer (stratum corneum) consists of nonviable, fully keratinized cells.

Staining with monoclonal antibody 16 recognizing the extracellular domain of the $\alpha_{5}$ subunit revealed only a faint and somewhat diffuse pattern in the fetal epidermis, while no reaction was detected in newborn and adult epidermis (Fig. 2, $g-i$ ). In fetal skin, prominent staining with antibody 16 was noted in association with inner root sheath of the hair follicle (Fig. $2 \mathrm{~g}$ ), whereas antibodies recognizing $\alpha_{2}$ and $\alpha_{3}$ integrin subunits stained the outer root sheath (Fig. 2, $a$ and $d$ ). Thus, the cutaneous structures of human epidermis and dermis demonstrate differential expression of the integrin $\alpha$ subunits. In particular, $\alpha_{2} / \beta_{1}$ and $\alpha_{3} / \beta_{1}$ integrins were expressed in the epidermis at all three different stages of development studied, whereas $\alpha_{5} / \beta_{1}$ integrin was readily detectable only in fetal skin. Consequently, the expression of $\alpha_{5} / \beta_{1}$ integrin may play a functional role during fetal development for high-affinity binding of fibronectin. In contrast, localization of the $\alpha_{2} / \beta_{1}$ and $\alpha_{3} / \beta_{1}$ inte- 

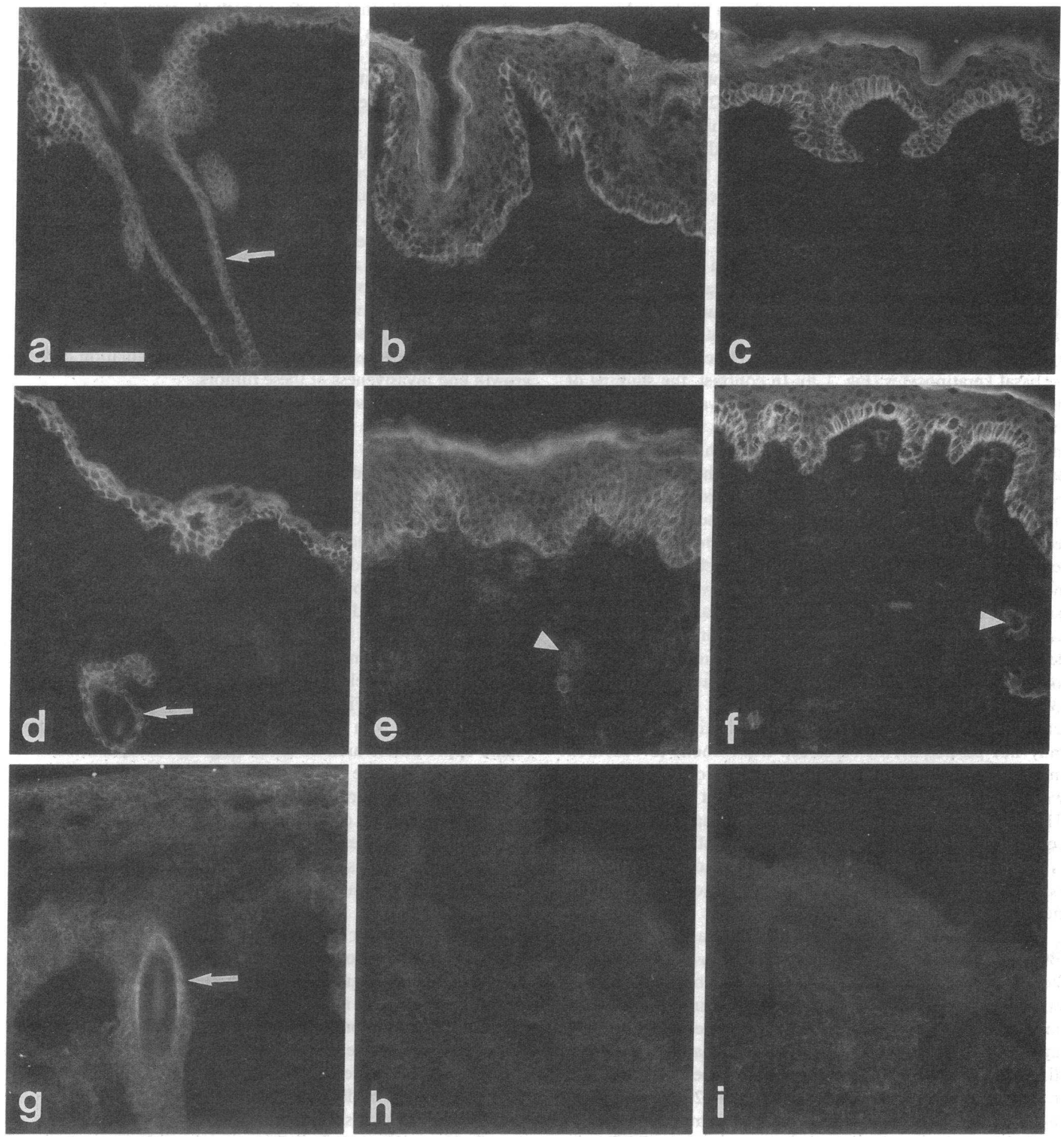

Figure 2. Expression of integrin receptors containing $\alpha_{2}(a-c), \alpha_{3}(d-f)$, or $\alpha_{5}(g-i)$ subunits in fetal (left), perinatal (middle), and adult (right column) human skin. Note the expression of $\alpha_{2}$ and $\alpha_{3}$ subunits in fetal, newborn, and adult skin, whereas $\alpha_{5}$ subunit is detected only in fetal skin. The expression of $\alpha_{2}$ and $\alpha_{3}$ subunits is localized in epidermis and the outer root sheath $(a$ and $d)$; the $\alpha_{5}$ subunit shows strong staining associated with the inner root sheath $(g)$ of the hair follicle (arrow). Faint, yet clearly detectable staining with $\alpha_{3}$ antibody of dermal vessels can be detected $(e, f)$ (arrowheads), although the same structures are essentially negative for staining with $\alpha_{2}$ and $\alpha_{5}$ antibodies. Bar, $100 \mu \mathrm{m}$.

grins juxtaposed to the basement membrane zone, which contains the ligand matrix components (see below), may provide continued stability to the epidermal-dermal interface. These observations are consistent with previous demonstrations that embryonic basement membranes contain fibronectin $(29,30)$, although this glycoprotein is apparently not an intrinsic component of adult basement membranes (31). The initial screening of the $\mathrm{J} 143$ antibody as a potential tumor marker, before its relationship to the integrins was established, showed reaction against the basal layer of epidermis (32). In addition, 
staining of the basal layer of human fetal skin has been demonstrated $(9,10)$ using extracellular matrix receptor I (ECMR I) antibodies, which were recently shown to identify the same $\alpha_{3}$ molecule as J143 (9). Similar staining was noted with antibodies to ECMRII which corresponds to VLA-2 receptor (10). It should also be noted that absence of staining may also be caused by masking, denaturation, or even destruction of the epitope. These observations, however, agree with those showing the absence of functional fibronectin receptor in freshly isolated human keratinocytes, according to biological assays $(33,34)$.

To examine the spatial distribution of a major basement membrane component that can be a potential ligand for $\alpha_{2} / \beta_{1}$ and $\alpha_{3} / \beta_{1}$ integrins, the same tissue specimens were stained with anti-type IV collagen antibodies. An intense linear staining pattern was noted in adult skin specimens juxtaposed to the basal keratinocytes (Fig. $1 h$ ). In contrast, the staining of the basement membrane zone in fetal skin was less prominent and more diffuse (Fig. $1 \mathrm{~g}$ ). Staining with type IV collagen antibody was also noted in association with dermal vascular structures both in fetal and adult skin. The localization of $\alpha_{3} / \beta_{1}$ integrins in the basal layer in the proximity of the dermal-epidermal basement membrane zone suggests that these receptors, at least in part, mediate the attachment of the basal cells to underlying basement membrane. Such binding may be mediated by laminin or type IV collagen which are integral parts of the basement membrane serving as ligands for the $\alpha_{3} / \beta_{1}$ integrin. In support of this suggestion is the previous demonstration that collagen and laminin are capable of promoting the attachment of human basal keratinocytes in vitro (35). The previously described subbasement membrane localization of fibronectin indicates that fibronectin-ligand binding may not participate in basal cell attachment to basement membrane, although the precise localization of fibronectin within the basement membrane zone is not entirely clear (4, $31)$. Although polyclonal antibodies to human fibronectin receptor prominently stained the basal layer of the epidermis, it is most likely that this binding was due to the $\beta_{1}$ subunit, because we failed to show any positive reaction with monoclonal antibodies directed to the $\alpha_{5}$ subunit.

$B C C$. The studies on normal human skin were extended to BCC. These cutaneous lesions have previously been shown to be rich in fibronectin, which localizes abundantly in the stroma of the lesions in the immediate proximity of basal cells of the tumor islands $(17,18)$. Recent studies using immunocytochemistry and in situ hybridization have demonstrated that fibronectin in BCC is of the cellular type, and is produced by the peripheral basal cells of this tumor (20). In addition to fibronectin, other basement membrane components, such as type IV collagen, can be shown to surround the BCC tumor island (Fig. 3, $a$ and $c$ ) (21). In most cases, the basement membrane, as visualized by staining with type IV collagen antibody, appeared intact (Fig. $3 a$ ), although occasional discontinuities were observed (Fig. 3 c). Similar observations have also been reported previously in ultrastructural analyses (36).

In the present study, staining of BCC with antibodies recognizing either the $\beta_{1}, \alpha_{2}, \alpha_{3}$, or $\alpha_{5}$ subunits of the integrin receptors revealed a selective expression in a manner resembling that of normal human epidermis. Specifically, the peripheral layer containing the basal cells demonstrated an intense intercellular staining with both the anti- $\beta_{1}$ and anti- $\alpha_{3}$ antibodies, and the most intense staining was noted on the surface of the cells that interfaced with the stroma (Fig. $3 b$ ). However, antibodies to the $\alpha_{2}$ subunit reacted poorly with BCC islands.

In areas demonstrating discontinuities in the basement membrane, as detected by antibodies to type IV collagen antibodies (Fig. $3 c$ ), the staining with anti- $\alpha_{3}$ antibodies showed less preferential staining for the basal keratinocytes located at the basement membrane-epithelial cell interface (Fig. $3 d$ ). Instead, more prominent suprabasal staining with a distinct intercellular reaction was noted, with staining extending rather uniformly around the perimeter of the cells. The latter type of staining pattern was also observed in fingerlike extensions of the basal cell carcinomas, which may represent sites of invasion of the tumors into adjacent normal tissue. Thus, it appears that intact basement membrane, through interactions mediated by integrins, may help to maintain regulation of the growth and invasiveness of these tumors.

Squamous cell carcinoma. For comparison, five squamous cell carcinomas were stained with the same battery of anti-integrin antibodies. In contrast, the staining pattern, using the same panel of antibodies as in case of BCC or normal skin, was patchy and discontinuous in different parts of the tumors in four lesions (Fig. 4). Clearly, the distribution of integrins in the squamous cell carcinoma lesions was different from BCC, and was not concentrated in the periphery. Staining of the same lesions with anti-type IV collagen antibody revealed the absence of an organized basement membrane in the periphery of the lesions, although faint, yet clearly detectable, staining with anti-type IV collagen antibodies could be detected within the lesions. Blood vessel-associated basement membranes were readily detectable (Fig. $4 a$ ). This internal staining of the lesions correlated with the presence of integrin receptors in the same approximate area of tissue (Fig. 4). Thus, there was a general concordance in the spatial expression of integrin receptors and their corresponding ligands in the squamous cell carcinomas. In one of the lesions, no staining reaction with any of the antibodies recognizing the four different types of integrin subunits was detected either by indirect immunofluorescence or with the more sensitive PAP technique (not shown).

Interestingly, our results with malignant human epidermal carcinomas differ from earlier in vivo findings analyzing the effect of viral malignant transformation on avian fibrocytes (37). In that study, integrin receptors were also found to be altered in distribution in Rous sarcoma virus-induced tumors, but their levels were increased, rather than unaltered or decreased as in the present studies of basal and squamous cell carcinomas. These differences might be due to the use of different species or tissue types, or to different pathogenetic mechanisms. Nevertheless, it is now clear, that a diversity of alterations in integrins will be found in malignancy.

Conclusions. Normal human skin predominantly expresses the $\alpha_{2} / \beta_{1}$ and $\alpha_{3} / \beta_{1}$ integrin receptor complexes in basal cells, with enrichment in sites interfacing with the basement membrane zone. However, integrin receptors were not restricted to the basement membrane-cell interface but were also found around the entire periphery of these cells, albeit often at reduced levels. These findings are of particular interest, since the intercellular spaces of these cells are not known to contain any ligands for the matrix receptors (i.e., fibronectin, laminin, or type IV collagen). We speculate that these receptors might have some previously unrecognized functions in cell-cell in- 

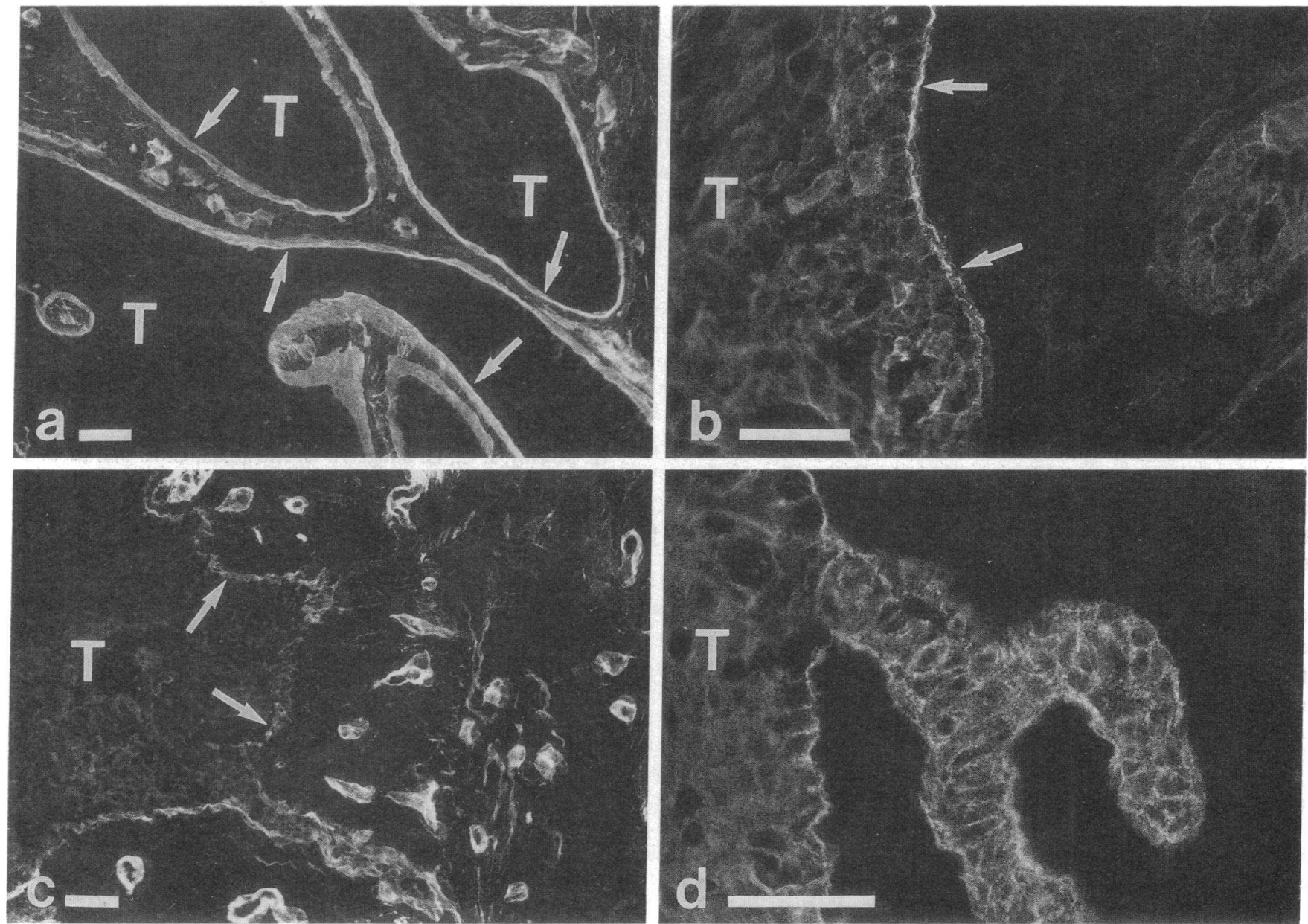

Figure 3. Immunostaining of BCC sections for type IV collagen ( $a$ and $c$ ) and the $\alpha_{3}$ integrin subunit $(b$ and $d$ ). In most areas, the basal cell tumor islands $(T)$ are surrounded by an intact basement membrane containing type IV collagen (arrows). Occasionally there are discontinuities and breaks in the basement membrane (panel $c$, arrows). In the areas containing a continuous basement membrane, $\alpha_{3}$ containing integrin receptors in the basal keratinocytes are juxtaposed to the basement membrane (panel $b$, arrows). In the areas demonstrating discontinuity of the basement membrane, extensions of the BCC show distinct intercellular and cell surface staining of keratinocytes $(d)$. Bar, $50 \mu \mathrm{m}$.
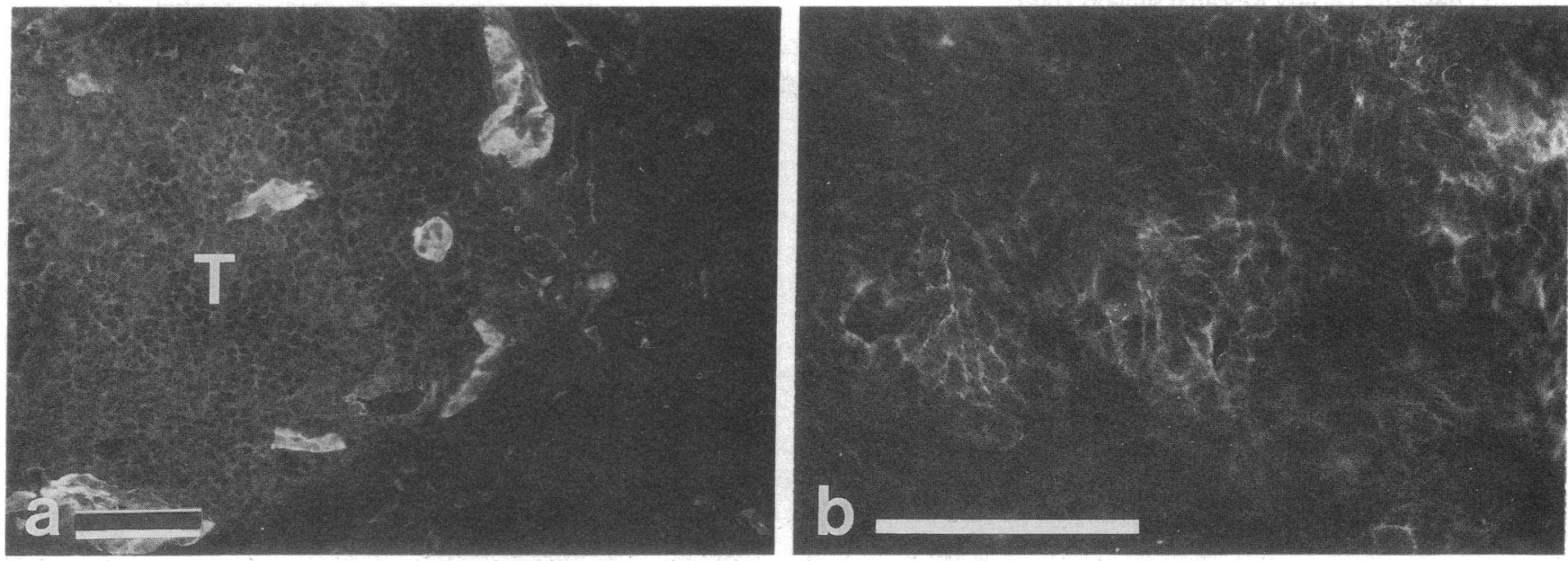

Figure 4. Staining of squamous cell carcinomas with anti-type IV collagen antibodies $(a)$ or with a polyclonal antibody recognizing both $\alpha_{5}$ and $\beta_{1}$ integrin receptor subunits $(b)$. Note the intralesional and intercellular staining reaction within the tumor $(T)$ with both antibodies. Similar pattern was noted with antibodies to $\alpha_{3}$ integrin subunit. Bar, $100 \mu \mathrm{m}$. 
teractions of epithelial cells, or these findings may suggest the presence of previously unrecognized ligands in the intercellular spaces of basal keratinocytes. An alternative explanation is that keratinocytes abundantly express integrins on their surface, and when the appropriate ligands are present (such as type IV collagen, laminin, and fibronectin in mature, adult basement membrane), the integrins are concentrated on these sites. When keratinocyte proliferation occurs and the cells are displaced from the basal lamina, integrin expression declines and their distribution becomes diffuse. This alternative explanation is supported by previous observations (38) that suggest that integrin location on cells is profoundly affected by the ligand.

In basal cell carcinomas, localization of $\alpha_{3} / \beta_{1}$ integrins was demonstrated in close proximity to apparently intact basement membrane. In the areas of fragmentation and discontinuity, integrin receptors did not preferentially localize to the epithelial-mesenchymal interface, but instead a suprabasal intercellular staining pattern was observed. These areas may well represent sites of invasion by this locally destructive tumor.

In squamous cell carcinomas, a variable staining pattern was observed. If present, the integrins were not at the periphery of the tumors, and occasional intralesional expression was detected. These observations possibly reflect impaired tumormatrix interactions, and may relate to the much more malignant phenotype of squamous cell carcinomas.

\section{Acknowledgments}

The authors thank Mary-Lou Gregory and Kathryn Gay for skillful technical assistance, Eileen O'Shaughnessy for her superb secretarial help, and Dr. Lloyd Old for the kind gift of J143 monoclonal antibody. Drs. Gary Lask, Steven Greenbaum, and Risto Penttinen kindly provided tissue specimens.

This study was supported in part by National Institutes of Health grants AM-28450, GM-28833, AR-35297, AR-38923, and T32 AR7561 and The Finnish Cultural Fund. Dr. Peltonen was a recipient of a Young Investigator Award from the National Neurofibromatosis Foundation, and Dr. Larjava is a recipient of the International Research Fellowship Award of Fogarty International Center, National Institutes of Health. Steven K. Akiyama was partially supported by National Institutes of Health grants CA-14718 and CA-45515 and a Howard University Faculty Research support grant.

\section{References}

1. Hynes, R. O., and K. M. Yamada. 1982. Fibronectins: multifunctional modular glycoproteins. J. Cell Biol. 95:369-377.

2. Nishida, T., S. Nakagawa, T. Awata, Y. Ohashi, K. Watanabe, and R. Manabe. 1983. Fibronectin promotes epithelial migration of cultured rabbit cornea in situ. J. Cell Biol. 97:1653-1657.

3. Clark, R. A. F., J. M. Folkvord, and R. L. Wertz. 1985. Fibronectin, as well as other extracellular matrix proteins, mediate human keratinocyte adherence. J. Invest. Dermatol. 84:378-383.

4. Martin, G. R., and R. Timpl. 1987. Laminin and other basement membrane components. Annu. Rev. Cell Biol. 3:57-85.

5. Hynes, R. O. 1987. Integrins: a family of cell surface receptors. Cell. 48:549-554.

6. Ruoslahti, E., and M. D. Pierschbacher. 1987. New perspectives in cell adhesion: RGD and integrins. Science (Wash. DC). 238:491497.

7. Juliano, R. L. 1987. Membrane receptors for extracellular matrix macromolecules: relationships to cell adhesion and tumor metastasis. Biochim. Biophys. Acta. 907:261-278.
8. Yamada, K. M. 1988. Fibronectin domains and receptors. In Fibronectin. D. F. Mosher, editor. Academic Press, Inc., New York. 47-121.

9. Takada, Y., E. A. Wayner, W. G. Carter, and M. E. Hemler. 1988. Extracellular matrix receptors, ECMRII and ECMRI, for collagen and fibronectin correspond to VLA-2 and VLA-3 in the VLA family of heterodimers. J. Cell. Biochem. 37:385-393.

10. Wayner, E. A., W. G. Carter, R. Piotrowicz, and T. J. Kunicki. 1989. The function of multiple extracellular matrix receptors in mediating cell adhesion to extracellular matrix: preparation of monoclonal antibodies to the fibronectin receptor that specifically inhibit cell adhesion to fibronectin and react with platelet glycoproteins Ic/IIa. $J$. Cell Biol. 107:1881-1891.

11. Takada, Y., J. L. Strominger, and M. E. Hemler. 1987. The very late antigen family of heterodimers is part of a superfamily of molecules involved in adhesion and embryogenesis. Proc. Natl. Acad. Sci. USA. 84:3239-3243.

12. Murray, J. C., G. Stingl, H. K. Kleinman, G. R. Martin, and S. I. Katz. 1979. Epidermal cells adhere preferentially to type IV (basement membrane) collagen. J. Cell Biol. 80:197-202.

13. O'Keefe, E. J., R. E. Payne, N. Russell, and D. T. Woodley. 1985. Spreading and enhanced motility of human keratinocytes on fibronectin. J. Invest. Dermatol. 85:125-130.

14. Sasaki, M., H. K. Kleinman, H. Huber, R. Deutzmann, and Y. Yamada. 1988. Laminin, a multidomain protein: the A chain has a unique globular domain and homology with the basement membrane proteoglycan and the laminin B chains. J. Biol. Chem. 263:1653616544.

15. Timpl, R., and M. Dziadek. 1986. Structure, development, and molecular pathology of basement membranes. Int. Rev. Exp. Pathol. 29:1-112.

16. Takashima, A., and F. Grinnel. 1984. Human keratinocyte adhesion and phagocytosis promoted by fibronectin. J. Invest. Dermatol. 83:352-358.

17. Nelson, D. L., C. D. Little, and G. Balian. 1982. Distribution of fibronectin and laminin in basal cell epitheliomas. J. Invest. Dermatol. 80:446-452.

18. Grimwood, R. E., J. C. Huff, J. W. Harbell, and R. A. F. Clark. 1984. Fibronectin in basal cell epithelioma: sources and significance. $J$. Invest. Dermatol. 82:145-149.

19. Grimwood, R. E., C. F. Ferris, L. D. Nielsen, J. C. Huff, and R. A. F. Clark. 1986. Basal cell carcinomas grown in nude mice produce and deposit fibronectin in the extracellular matrix. J. Invest. Dermatol. 87:42-46.

20. Peltonen, J., S. Jaakkola, G. Lask, I. Virtanen, and J. Uitto. 1988. Fibronectin gene expression by epithelial tumor cells in basal cell carcinomas: an immunocytochemical and in situ hybridization study. J. Invest. Dermatol. 91:289-293.

21. Van Cauwenberge, D., G. E. Pierard, J. M. Foidart, and C. M. Lapiere. 1983. Immunohistochemical localization of laminin, type IV and type $\mathrm{V}$ collagen in basal cell carcinoma. Br. J. Dermatol. 198:163-170.

22. Peltonen, J., S. Jaakkola, M. Lebwohl, S. Renvall, L. Risteli, I. Virtanen, and J. Uitto. 1988. Cellular differentiation and expression of matrix genes in type 1 neurofibromatosis. Lab. Invest. 59:760-771.

23. Roberts, C. J., T. M. Birkenmeier, J. J. McQuillan, S. K. Akiyama, S. S. Yamada, W.-T. Chen, K. M. Yamada, and J. A. McDonald. 1988. Transforming growth factor $\beta$ stimulates the expression of fibronectin and both subunits of the human fibronectin receptor by cultured human lung fibroblasts. J. Biol. Chem. 263:4586-4592.

24. Rettig, W. J., N. C. Dracopoli, T. A. Goetzger, B. A. Spengler, J. L. Biedler; H. F. Oettgen, and L. J. Old. 1984. Somatic cell genetic analysis of human cell surface antigens: chromosomal assignments and regulation of expression in rodent-human hybrid cells. Proc. Natl. Acad. Sci. USA. 81:6437-6441.

25. Rettig, W. J., V. V. V. S. Murty, M. J. Mattes, R. S. K. Chaganti, and L. J. Old. 1986. Extracellular matrix-modulated expression of human cell surface glycoproteins A42 and J143: intrinsic and ex- 
trinsic signals determine antigenic phenotype. J. Exp. Med. 164:1581-1599.

26. Gralnick, H. R., L. P. McKeown, S. S. Williams, J. L. Lawrence, B. C. Schafer, W. S. Kramer, K. E. Hansmann, M. L. Vail, and L. E. Magruder. 1988. A murine monoclonal antibody that identifies a $157 / 130 \mathrm{kDa}$ platelet-collagen receptor. Circulation. 78(Suppl. II):308. (Abstr.)

27. Akiyama, S. K., S. S. Yamada, W.-T. Chen, and K. M. Yamada. 1989. Analysis of fibronectin receptor function with monoclonal antibodies: roles in cell adhesion, migration, matrix assembly, and cytoskeletal organization. J. Cell Biol. 109:863-875.

28. De Strooper, B., B. Van Der Schueren, M. Jaspers, M. Saison, M. Spaepen, F. Van Leuven, H. Van Den Berghe, and J.-J. Cassiman. 1989. Distribution of the $\beta 1$ subgroup of the integrins in human cells and tissues. J. Histochem. Cytochem. 37:299-307.

29. Stenman, S., and A. Vaheri. 1978. Distribution of a major connective tissue protein, fibronectin, in normal human tissues. $J$. Exp. Med. 147:1054-1064.

30. Wartiovaara, J., I. Leivo, and A. Vaheri. 1979. Expression of the cell surface associated glycoprotein, fibronectin, in the early mouse embryo. Dev. Biol. 69:247-257.

31. Martinez-Hernandez, A., and P. S. Amenta. 1983. The basement membrane in pathology. Lab. Invest. 48:656-677.
32. Fradet, Y., C. Cordon-Cardo, T. Thomson, M. E. Daly, W. F. Whitmore, Jr., K. O. Lloyd, M. R. Melamed, and L. J. Old. 1984. Cell surface antigens of human bladder cancer defined by mouse monoclonal antibodies. Proc. Natl. Acad. Sci. USA. 81:224-228.

33. Toda, K.-I., T.-L. Tuan, P. J. Brown, and F. Grinnell. 1987. Fibronectin receptors of human keratinocytes and their expression during cell culture. J. Cell Biol. 105:3097-3104.

34. Takashima, A., R. E. Billingham, and F. Grinnell. 1986. Activation of rabbit keratinocyte fibronectin receptor function in vivo during wound healing. J. Invest. Dermatol. 86:585-590.

35. Stanley, J. R., J. M. Foidart, J. C. Murray, G. R. Martin, and S. I. Katz. 1980. The epidermal cell which selectively adheres to a collagen substrate is the basal cell. J. Invest. Dermatol. 74:54-58.

36. McNutt, N. S. 1976. Ultrastructural comparison of the interface between epithelium and stroma in basal cell carcinoma and control human skin. Lab. Invest. 35:132-142.

37. Saga, S., W.-T. Chen, and K. M. Yamada. 1988. Enhanced fibronectin receptor expression in Rous sarcoma virus-induced tumors. Cancer Res. 48:5510-5513.

38. Duband, J. L., G. H. Nuckolls, A. Ishihara, T. Hasegawa, K. M. Yamada, J. P. Thiery, and K. Jacobson. 1988. Fibronectin receptor exhibits high lateral mobility in embryonic locomoting cells but is immobile in focal contacts and fibrillar streaks in stationary cells. $J$. Cell Biol. 107:1385-1396. 